\title{
Gel Electrophoresis Chip using Joule Heat Self-dissipation, Short Run Time and Online Dynamic Imaging
}

Jingjing Xue, ${ }^{\nabla \dagger \mid}$ Qiang Zhang, ${ }^{\nabla \dagger}$ Jun Cao, ${ }^{\dagger}$ Youli Tian, ${ }^{\dagger \mid}$ Genhan Zha, ${ }^{\dagger}$ Xiaoping Liu, ${ }^{\dagger}$ Weiwen Liu, ${ }^{\dagger}$ Yuxing Wang, ${ }^{i}$ Dingkun Gui, ${ }^{+*}$ and Chengxi Cao, $\left.{ }^{\dagger \neq}\right|^{*}$

${ }^{\dagger}$ Department of Instrument Science and Engineering, School of Electronic Information and Electrical Engineering, Shanghai Jiao Tong University, Shanghai 200240, P. R. China

${ }^{*}$ Shanghai Jiao Tong University Affiliated Sixth People's Hospital, Shanghai 200233, P. R. China

'School of Life Science and technology, Shanghai Jiao Tong University, Shanghai 200240, P. R. China

'School of Physics and Astronomies, Shanghai Jiao Tong University, Shanghai 200240, P. R. China

S1. Comparison of TCP chip, PMMA Chip and Traditional Slab Gel

S2. Simulations

S2.1. Simulation on temperature distribution of in TCP and PMMA chips

S2.2. Simulation on dynamic migration of model proteins in TCP and PMMA chips

S2.3. Simulation on protein bands broadening with temperature / time gradient

S3. Experimental Validations

S3.1. Experiments on center temperature of TCP and PMMA chips at different voltages

S4. Analytical Performance

S4.1. Experiments on uniformity

S4.2. Experiments on traditional slab GE of model proteins

S5. Protein Separation and Identification via Traditional Slab GE and HRMS

S5.1. Experiments on traditional slab GE of healthy adult human blood sample

S5.2. Identification of $\mathrm{Hb}$ variants in blood sample by high resolution mass spectrometry (HRMS)

S6. TCP SDS GE Chip of Standard MW Markers and Model Proteins

S7. Material Thermal Conductivity

S8. Simulation Parameters

S9. Blood Samples and Isoelectric Focusing (IEF) 


\section{S1. Comparison of TCP chip, PMMA Chip and Traditional Slab Gel}

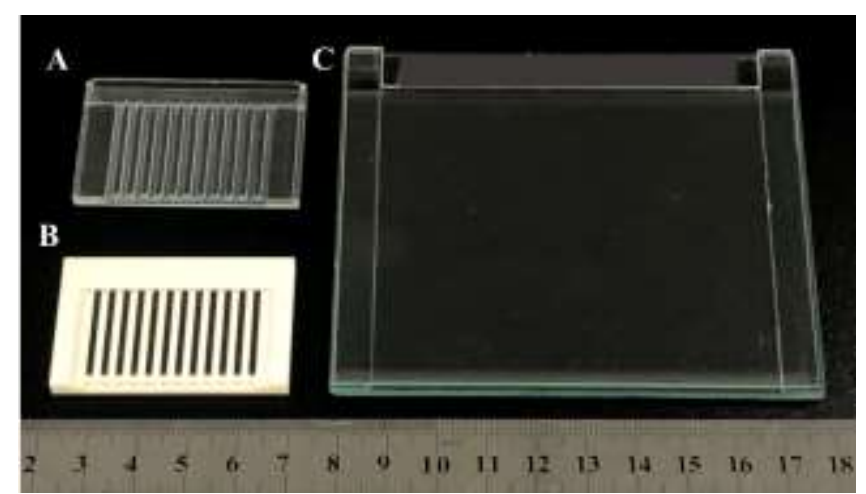

Figure S1. Image of the PMMA chip (A), the TCP chip (B) and the traditional slab gel $(\mathbf{C})$.

\section{S2. Simulations}

\section{S2.1. Simulation on temperature distribution in TCP and PMMA chips}
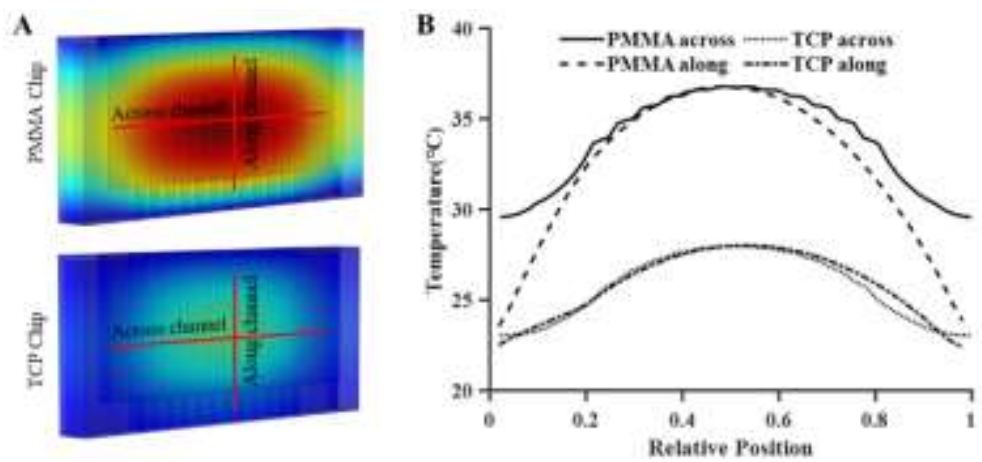

Figure S2. Simulations on infrared thermal imaging in PMMA (up) and TCP(down) GE chips (A) and temperature distribution across and along the channel of PMMA and TCP chips (B) after 600 sec run of gel electrophoresis.

\section{S2.2. Simulation on dynamic migration of model proteins in TCP and PMMA chips}
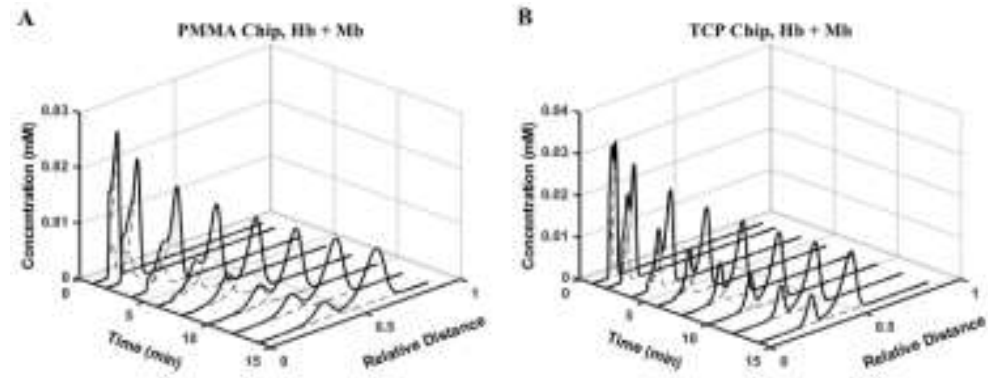

Figure S3. Simulations on dynamic migration of two model proteins of $\mathrm{Hb}$ and $\mathrm{Mb}$ in PMMA (A) and TCP (B) GE chips under different running times. 


\section{S2.3. Simulation on protein bands broadening with temperature / time gradient}

A
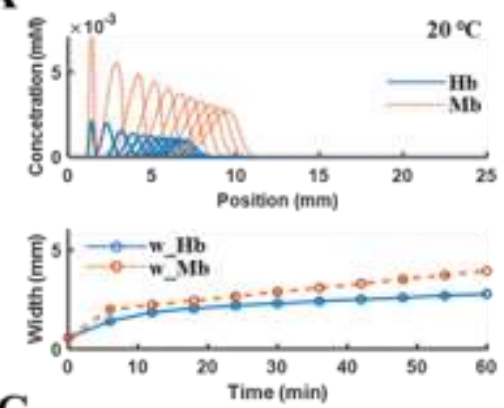

C
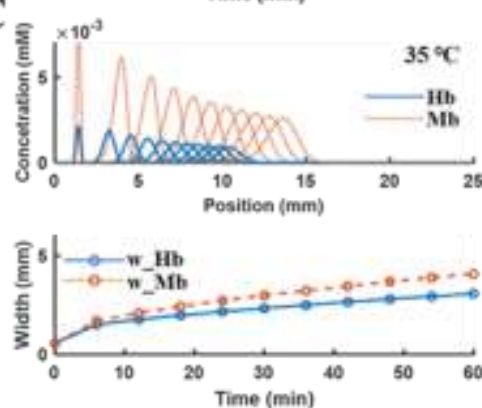

$\mathbf{E}$
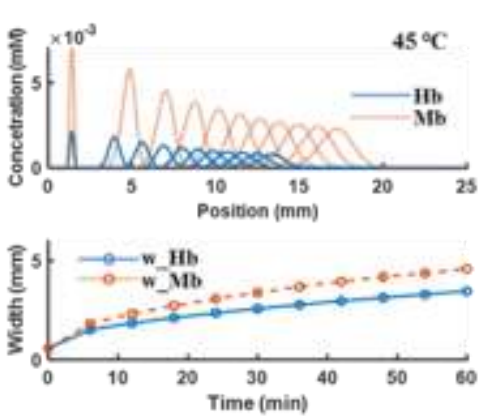

B
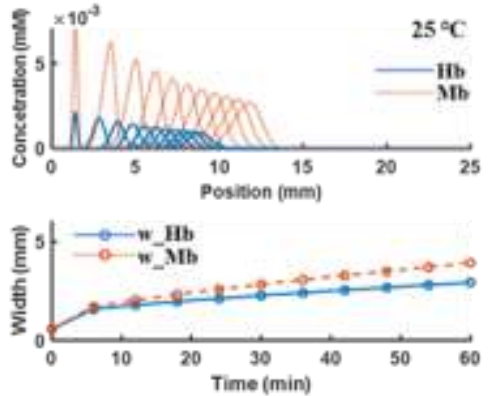

D
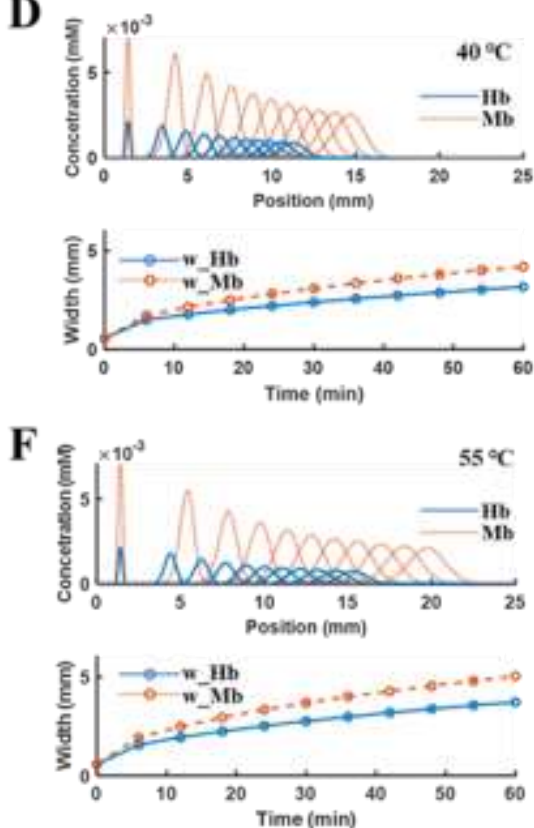

Figure S4. Simulation results of $\mathrm{Hb}$ and $\mathrm{Mb}$ separation in a $50 \mathrm{~mm}$ length channel under the temperatures of (A) $\mathrm{T}=20{ }^{\circ} \mathrm{C},(\mathbf{B}) \mathrm{T}=25{ }^{\circ} \mathrm{C},(\mathbf{C}) \mathrm{T}=35{ }^{\circ} \mathrm{C},(\mathbf{D}) \mathrm{T}=40{ }^{\circ} \mathrm{C},(\mathbf{E}) \mathrm{T}=45{ }^{\circ} \mathrm{C}$ and $(\mathbf{F}) \mathrm{T}=55^{\circ} \mathrm{C}$. Simulation conditions: the running time was set within $60 \mathrm{~min}$, the time interval was 6 min between two adjacent peaks of same protein, the initial band width was set as $0.1 \mathrm{~mm}$, and the others were the same as those in the experimental conditions of $\mathbf{S 8}$.

In the simulations of Figure S4 (e.g., Panel A or Panel B), the two model proteins of $\mathrm{Hb}$ and $\mathrm{Mb}$ were separated in an electrophoretic chip with $50 \mathrm{~mm}$ lanes in $60 \mathrm{~min}$. Clearly, both $\mathrm{Hb}$ and $\mathrm{Mb}$ peaks kept broadening gradually with the increasing of running time, and the peak shapes tended to be wide and diluted. Such simulative results were mutually in coincidence with the experimental results if assuming the initial band width was $0.1 \mathrm{~mm}^{\mathrm{S} 1}$ in Figure 4, validating eq 11 that the band widths $(w(t))$ had a partial parabolic relationship with running time $(t)$ when the temperature $(T)$ was set as a constant under certain boundary conditions of long running lanes and long running time. The simulations of $35,40,45$ and $55{ }^{\circ} \mathrm{C}$ in Figure S4C-S4F further showed the partial parabolic relationship. In addition, if the simulation time was increased to $240 \mathrm{~min}$, the parabolic curve tends to be saturated as shown in Figure S5. 

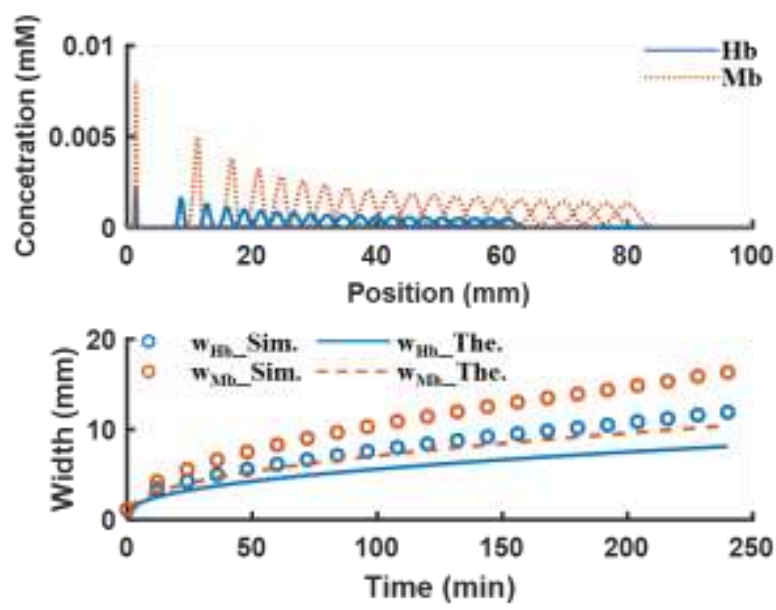

Figure S5. Comparison of simulative results and theoretical results of $\mathrm{Hb}$ and $\mathrm{Mb}$ separating in a $100 \mathrm{~mm}$ length channel for $240 \mathrm{~min}$ under the temperatures of $25^{\circ} \mathrm{C}$. Simulation conditions were given in Figure S4.

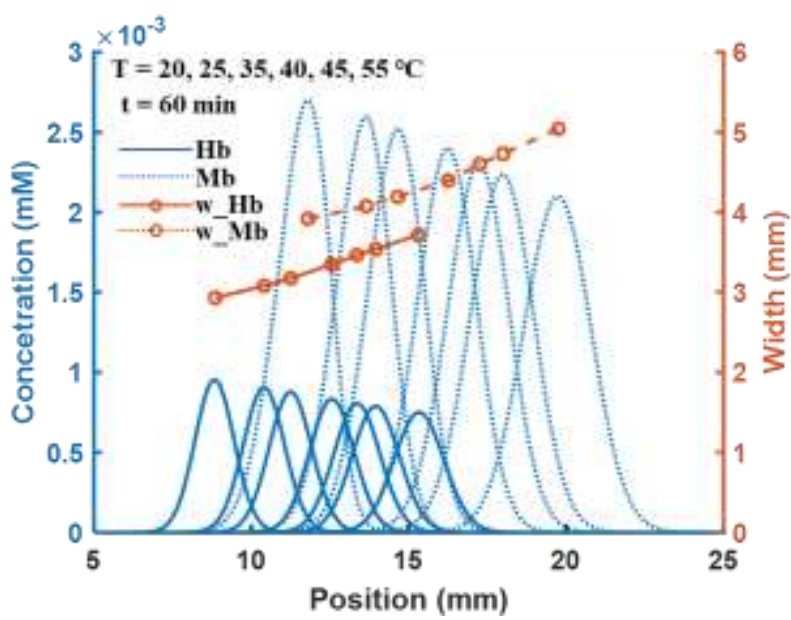

Figure S6. Separation simulations of $\mathrm{Hb}$ (solid blue line) and $\mathrm{Mb}$ (dotted blue line) in a $50 \mathrm{~mm}$ length channel under different ambient temperature $\left(\mathrm{T}=20,25,35,40,45\right.$ and $\left.55^{\circ} \mathrm{C}\right)$. Simulation conditions: the running time was $60 \mathrm{~min}$, and the others were given in Figure S4.

The simulations in Figure S6 further showed that $\mathrm{Mb}$ and $\mathrm{Mb}$ were separated in the electrophoretic chip with $50 \mathrm{~mm}$ lanes after $60 \mathrm{~min}$ electrophoretic run under the different temperature ( $\mathrm{T}=20,25,35,40,45$ and $\left.55^{\circ} \mathrm{C}\right)$. In general, higher temperature resulted in wider peaks of two proteins of $\mathrm{Hb}$ and $\mathrm{Mb}$. However, the band widths $(w(t))$ had a proportional but not a partial parabolic relationship with temperature $(T)$ if the running time $(t)$ was a constant under certain boundary conditions of long running lanes and long running time. The simulations could not indicate the validity of eq 11 seemly due to the following reason.

Because the temperature of GE should be normally controlled within $25-45^{\circ} \mathrm{C}$ due to protein denature at high temperature. The change of GE temperature changing from about $298 \mathrm{~K}$ to $318 \mathrm{~K}$ led to highly sharp alteration, resulting in a seemly linear relation between the protein band with and the electrophoretic temperature. Thus, in a real GE run in room environment, the temperature could be approximately considered as a coefficient. 


\section{S3. Experimental Validations}

\section{S3.1. Experiments on center temperature of TCP \& PMMA chips at different voltages}

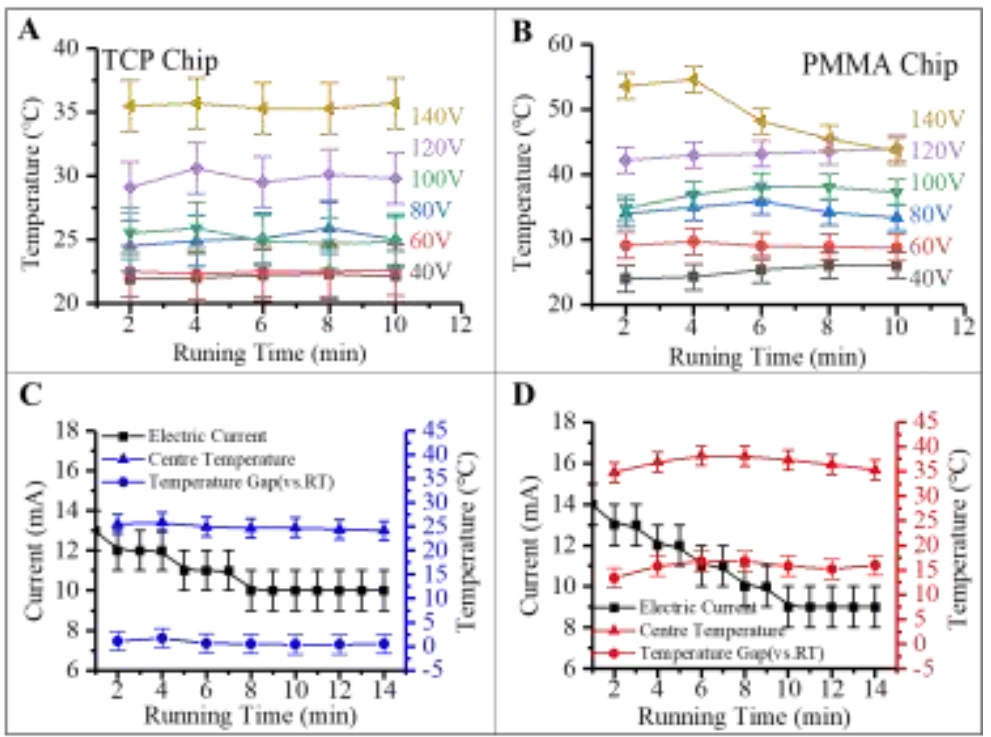

Figure S7. Experiments on centre temperature of TCP (A) and PMMA (B) chips in 10 min GE runs at voltages of 40-140 V; and electric current and temperature tendencies of TCP (C) and PMMA (D) chips in 10 min GE runs at $100 \mathrm{~V}$. There were about $10 \%$ error bars on infrared thermal imager.

As shown in PMMA chip (Figure S6B), the temperature at $140 \mathrm{~V}$ increased rapidly within the first two minutes and then dropped gradually as the running time increased. The relevant mechanism was induced by the following reason. Normally, the electric current of electrophoresis decreased gradually in zone electrophoresis due to buffer electrolysis. The strong electric field of $140 \mathrm{~V}$ could accelerate the buffer electrolysis and decrease the buffer conductivity in electrophoretic lanes, resulting in the obvious decrease of current (as shown in black line in Figure S6C and S6D).

The generation of Joule heat was proportional to the square of the current, namely there was the equation of $Q \propto R^{2}$. In PMMA chip with poor heat dispersion, Joule heat generation and accumulation led to temperature raising rapidly, thus when heat source (electric current) weakened, temperature decreased. This phenomenon has been observed repetitively when high voltage applied. Understandably, the temperature of TCP chip (Figure S6A) with good heat dispersion remained stable after about 2 min running under applied electric field from $40-140 \mathrm{~V}$ due to the satisfied heat dissipation of TCP chip framework. The comparison of Figure S6 demonstrated the relevant stability of Joule heating control achieved by the TCP chip rather than PMMA chip.

\section{S4. Analytical Performance}

\section{S4.1. Experiments on uniformity}



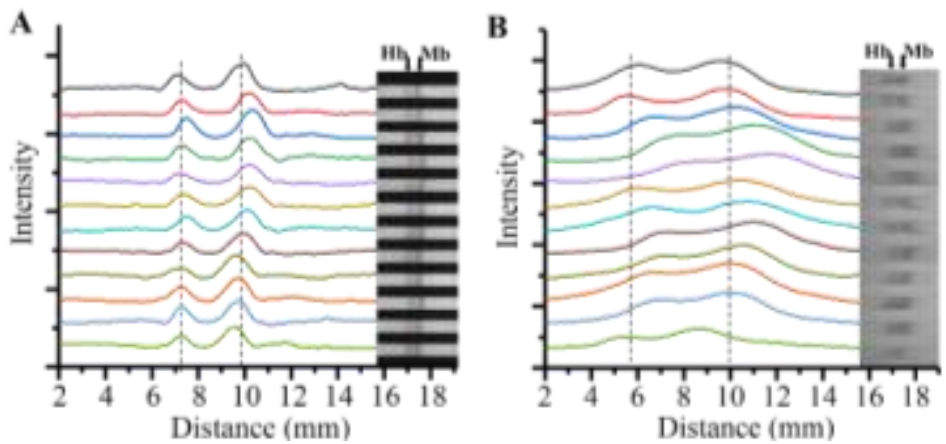

Figure S8. Experiments on uniformity of model protein electromigration of $\mathrm{Hb}$ and $\mathrm{Mb}$ in 12 channels of TCP (A) and PMMA (B) chip GE runs.

\section{S4.2. Experiments on traditional slab GE of model proteins}

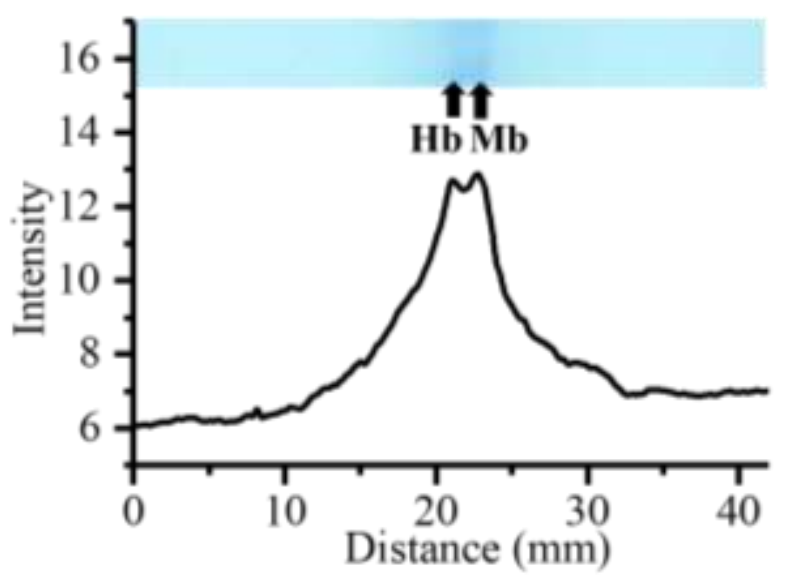

Figure S9. Experiments on traditional slab polyacrylamide gel electrophoresis of two model proteins of $\mathrm{Hb}$ and $\mathrm{Mb}$ (each at concentration of $1 \mu \mathrm{g} \mu \mathrm{L}^{-1}$ ) with staining of Coomassie brilliant blue.

\section{S5. Protein Separation and Identification via Traditional Slab GE and HRMS}

\section{S5.1. Experiments on traditional slab GE of healthy adult human blood sample}

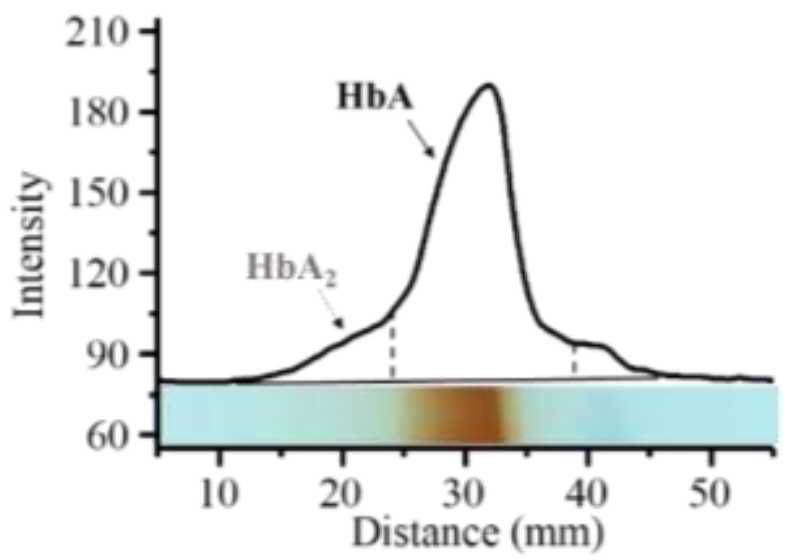

Figure S10. Experiments on alkaline conventional slab polyacrylamide gel electrophoresis of healthy 
adult blood sample.

\section{S5.2. Identification of $\mathrm{Hb}$ variants in blood sample by high resolution mass spectrometry (HRMS)}

4 bands (1 4) of 2 human blood samples in TCP GE were carefully excised, combined and identified by Q Exactive HF Hybrid Quadrupole-Orbitrap mass spectrometer (Thermo Fisher Scientific, MA, U.S.A.) system equipped with a nano-ESI (HRMS). Data were collected and processed on Xcalibur software (Thermo Fisher Scientific, MA, U.S.A.) and TraceFinder software (Thermo Fisher Scientific, MA, USA).

HRMS spectra of tryptic peptides obtained from the main band (band 2) showed sequence coverage of 100\% for the $\beta$ globin chain and $100 \%$ for $\alpha$ globin chain, strongly indicating the species of $\mathrm{HbA}$ thanks to double alpha and double beta globin chains (Table S2) and the predominant form of $\mathrm{HbA}$ in healthy adult blood sample. And the weaker band (band 1) has the sequence coverage of $84 \%$ for the delta globin chain with 5 unique peptides. It was likely to be $\mathrm{HbA}_{2}$, owing for double alpha and double delta globin chains and its molecular weight slightly higher than HbA. For infant DBS sample, the gamma globin chain of $\mathrm{HbF}(2 \alpha 2 \gamma)$ was recovered mostly in band 3 (65\% coverage). And small amount of $\mathrm{HbA}$ were recovered from band 4 . There was also band 5 appeared in DBS sample, which could not be identified via HRMS. The species might be the decomposition of $\mathrm{HbF}$ and $\mathrm{HbA}$ due to long term storage of DBS in room temperature. 
Table S1. HRMS profiling results of trypsin digested protein in band 1, 2, 3 and 4.

\begin{tabular}{|c|c|c|c|c|c|c|}
\hline & Band & Description & $\begin{array}{c}\text { Molecular } \\
\text { weight }[\mathrm{kDa}]\end{array}$ & $\begin{array}{l}\text { Unique } \\
\text { Peptides }\end{array}$ & $\begin{array}{c}\text { Sequence } \\
\text { coverage [\%] }\end{array}$ & Peptide Sequences \\
\hline \multirow{4}{*}{$\begin{array}{c}\text { Adult } \\
\text { fresh } \\
\text { blood } \\
\text { sample }\end{array}$} & \multirow[t]{2}{*}{1} & $\begin{array}{c}\text { Hemoglobin } \\
\text { subunit delta } \\
\text { Homo sapiens }\end{array}$ & 16 & 5 & 84 & $\begin{array}{l}\text { MVHLTPEEKT AVNALWGKVN VDAVGGEALG RLLVVYPWTQ RFFESFGDLS SPDAVMGNPK } \\
\text { VKAHGKKVLG AFSDGLAHLD NLKGTFSQLS ELHCDKLHVD } \\
\text { PENFRLLGNV LVCVLARNFG KEFTPQMQAA YQKVVAGVAN ALAHKYH }\end{array}$ \\
\hline & & $\begin{array}{l}\text { Hemoglobin } \\
\text { subunit alpha } \\
\text { Homo sapiens }\end{array}$ & 20.1 & 1 & 95 & $\begin{array}{l}\text { MVLSPADKTN VKAAWGKVGA HAGEYGAEAL ERMFLSFPTT KTYFPHFDLS HGSAQVKGHG } \\
\text { KKVGAHAGEY GAEALERMFL SFPTTKTYFP HFDLSHGSAQ } \\
\text { VKGHGKKVAD ALTNAVAHVD DMPNALSALS DLHAHKLRVD PVNFKLLSHC LLVTLAAHLP } \\
\text { AEFTPAVHAS LDKFLASVST VLTSKYR }\end{array}$ \\
\hline & \multirow[t]{2}{*}{2} & $\begin{array}{l}\text { Hemoglobin } \\
\text { subunit alpha } \\
\text { Homo sapiens }\end{array}$ & 20.1 & 1 & 100 & $\begin{array}{l}\text { MVLSPADKTN VKAAWGKVGA HAGEYGAEAL ERMFLSFPTT KTYFPHFDLS HGSAQVKGHG } \\
\text { KKVGAHAGEY GAEALERMFL SFPTTKTYFP HFDLSHGSAQ } \\
\text { VKGHGKKVAD ALTNAVAHVD DMPNALSALS DLHAHKLRVD PVNFKLLSHC LLVTLAAHLP } \\
\text { AEFTPAVHAS LDKFLASVST VLTSKYR }\end{array}$ \\
\hline & & $\begin{array}{l}\text { Hemoglobin beta } \\
\text { chain (Fragment) } \\
\text { Homo sapiens }\end{array}$ & 11 & 10 & 100 & $\begin{array}{l}\text { MVHLTPEEKS AVTALWGKVN VDEVGGEALG RLLVVYPWTQ RFFESFGDLS TPDAVMGNPK } \\
\text { VKAHGKKVLG AFSDGLADLD NLKGTFATLS ELHCDKLHVD } \\
\text { PENFR }\end{array}$ \\
\hline \multirow{4}{*}{$\begin{array}{l}\text { Infant dry } \\
\text { blood } \\
\text { sample }\end{array}$} & \multirow[t]{2}{*}{3} & $\begin{array}{c}\text { Hemoglobin } \\
\text { subunit alpha } \\
\text { Homo sapiens }\end{array}$ & 20.1 & 1 & 100 & $\begin{array}{l}\text { MVLSPADKTN VKAAWGKVGA HAGEYGAEAL ERMFLSFPTT KTYFPHFDLS HGSAQVKGHG } \\
\text { KKVGAHAGEY GAEALERMFL SFPTTKTYFP HFDLSHGSAQ } \\
\text { VKGHGKKVAD ALTNAVAHVD DMPNALSALS DLHAHKLRVD PVNFKLLSHC LLVTLAAHLP } \\
\text { AEFTPAVHAS LDKFLASVST VLTSKYR }\end{array}$ \\
\hline & & $\begin{array}{l}\text { Hemoglobin } \\
\text { subunit gamma-1 } \\
\text { Homo sapiens }\end{array}$ & 16.1 & 1 & 65 & $\begin{array}{l}\text { MGHFTEEDKA TITSLWGKVN VEDAGGETLG RLLVVYPWTQ RFFDSFGNLS SASAIMGNPK } \\
\text { VKAHGKKVLT SLGDAIKHLD DLKGTFAQLS ELHCDKLHVD } \\
\text { PENFKLLGNV LVTVLAIHFG KEFTPEVQAS WQKMVTAVAS ALSSRYH }\end{array}$ \\
\hline & \multirow[t]{2}{*}{4} & $\begin{array}{c}\text { Hemoglobin } \\
\text { subunit alpha } \\
\text { Homo sapiens }\end{array}$ & 20.1 & 1 & 86 & $\begin{array}{l}\text { MVLSPADKTN VKAAWGKVGA HAGEYGAEAL ERMFLSFPTT KTYFPHFDLS HGSAQVKGHG } \\
\text { KKVGAHAGEY GAEALERMFL SFPTTKTYFP HFDLSHGSAQ } \\
\text { VKGHGKKVAD ALTNAVAHVD DMPNALSALS DLHAHKLRVD PVNFKLLSHC LLVTLAAHLP } \\
\text { AEFTPAVHAS LDKFLASVST VLTSKYR }\end{array}$ \\
\hline & & $\begin{array}{l}\text { Hemoglobin beta } \\
\text { chain (Fragment) } \\
\text { Homo sapiens }\end{array}$ & 11 & 2 & 91 & $\begin{array}{l}\text { TPEEKSAVTA LWGKVNVDEV GGEALGRLLV VYPWTQRFFE SFGDLSTPDA VMGNPKVKAH } \\
\text { GKKVLGAFSN GLAHLDNLKG TFATLSELHC DKLHVDPENF } \\
\text { R }\end{array}$ \\
\hline
\end{tabular}




\section{S6. TCP SDS GE Chip of Standard MW Markers and Model Proteins}

$10 \%$ PA gel solution containing $0.1 \%$ (w/v) SDS was used as separation gel for both chip and slab gel SDS GE. And 5\% PA stacking gel containing 0.1\%(w/v) SDS is needed in slab gel SDS GE. $250 \mathrm{mmol} / \mathrm{L}$ Tris-Gly (pH 8.6) with $0.1 \%(w / v)$ SDS was used as the running buffer. Each well of the slab gel was loaded with $10 \mu \mathrm{L}$ of the protein sample solution, while $1 \mu \mathrm{L}$ was loaded into each gel channel in chips. The slab gel SDS-PAGE was performed, fixed and stained under the same condition of native slab gel PAGE described in Experiment section. And chip gel running condition is as same as native chip GE. To visualize colourless model proteins, Instant View ${ }^{\mathrm{TM}}$ protein staining and loading buffer (Beyotime Biotechnology, Shanghai, China) was used. A $450 \mathrm{~nm}$ longpass emission filter (Xinzhao optical, Shenzhen, China) and a $365 \mathrm{~nm}$ UV LED excitation source (GHUV, Shenzhen, China) were used for fluorescent image capture.

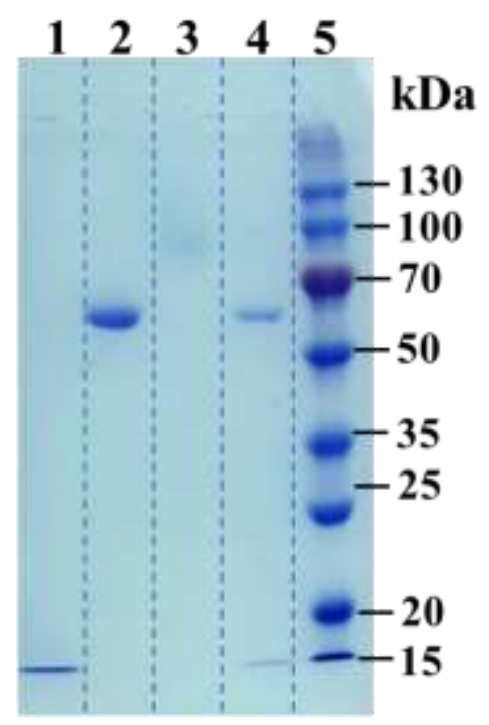

Figure S11. Slab SDS GE of lysozyme (Lane1), BSA (Lane2), $\beta$-galactosidase (Lane3), mixture of three model proteins (Lane4) and standard protein molecular weight markers (Lane5). The concentrations are $1 \mu \mathrm{g}$ per band for single protein samples, and $500 \mathrm{ng}$ per band for mixture of three model proteins.
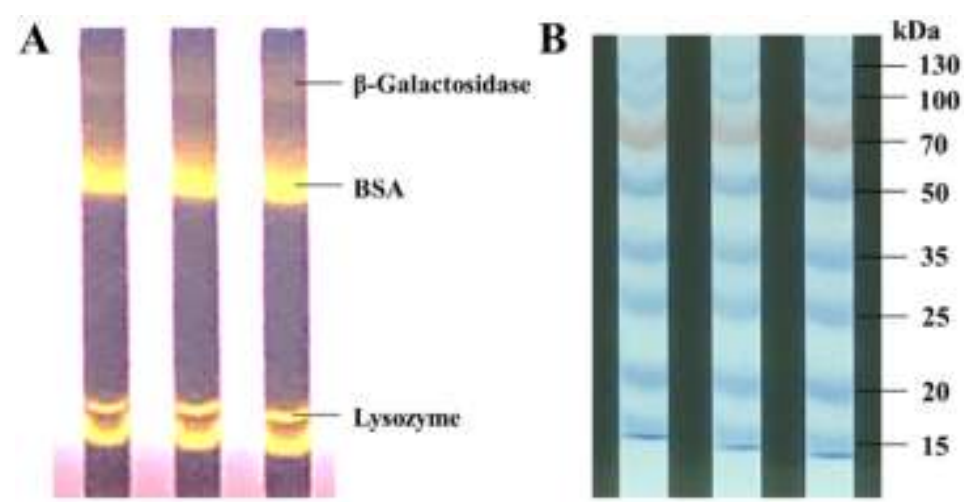

Figure S12. TCP chip SDS GE of model proteins (A) and conventional range protein marker (B). Concentration of protein sample is $1 \mu \mathrm{g}$ per band, and $1 \mu \mathrm{L}$ sample solution was loaded into each channel of TCP chip. 
Table S2. Comparation of SDS GE running features of TCP chip gel and slab gel.

\begin{tabular}{|l|l|l|l|}
\hline & TCP chip & PMMA chip & Slab gel \\
\hline Running time $[\mathrm{min}]$ & 6 & 6 & 60 \\
\hline Electric field intensity $\left[\mathrm{V} \mathrm{cm}^{-1}\right]$ & 50 & 50 & 12 \\
\hline Length of channel/lane $[\mathrm{mm}]$ & 20 & 20 & 75 \\
\hline Gel Consumption $[\mathrm{mL}]$ & 0.24 & 0.24 & 7.0 \\
\hline Protein Marker Consumption $[\mu \mathrm{L}]$ & 1 & 1 & 10 \\
\hline Buffer Consumption $[\mathrm{mL}]$ & 10 & 10 & $\sim 1000$ \\
\hline Stacking Gel & No & No & Yes \\
\hline Online Dynamic Imaging $(\mathrm{ODI})$ & Yes & Yes & No \\
\hline
\end{tabular}

\section{S7. Material Thermal Conductivity}

The thermal parameters of materials used herein were measured by the laser flash method (LFA 467, NETZSCH-Gerätebau GmbH, Germany) in line with the user introduction. The experimental data for the thermal conductivity of the thermal conductivity plastics, PMMA and glasses etc were listed in Table S3.

Table S3. Thermal data of 4 main chip materials and water.

\begin{tabular}{|l|c|c|c|c|}
\hline & $\begin{array}{c}\text { Temperature } \\
{\left[{ }^{\circ} \mathrm{C}\right]}\end{array}$ & $\begin{array}{c}\text { Thermal Conductivity } \\
{\left[\mathrm{W} \mathrm{m}^{-1} \mathrm{~K}^{-1}\right]}\end{array}$ & $\begin{array}{c}\text { Thermal Diffusivity } \\
{\left[\mathrm{mm}^{2} \mathrm{~s}^{-1}\right]}\end{array}$ & $\begin{array}{c}\text { Heat Capacity } \\
{\left[\mathrm{J} \mathrm{g}^{-1} \mathrm{~K}^{-1}\right]}\end{array}$ \\
\hline PMMA & 25 & 0.151 & 0.146 & 1.031 \\
\hline TCP & 25 & 5.605 & 2.340 & 2.395 \\
\hline Glass & 25 & 0.901 & 0.518 & 1.739 \\
\hline Quartz & 25 & 1.262 & 0.792 & 1.593 \\
\hline Water $^{\mathrm{S} 2}$ & 25 & 0.590 & 0.143 & 4.200 \\
\hline
\end{tabular}

\section{S8. Simulation Parameters and Comparations}

The heater transfer control equation was given in the manuscript, namely eq 12 . The geometric model for temperature was set as a 3-dimension model which was given in the Figure S2 (the total chip size was same as the real device, see GE Chip Device in manuscript). For simple calculation, we set the heat source in the gel base on the experimental conditions. Here, we set the heat dissipation during the electrophoresis as a constant (calculated according the voltage and current, see Figure S7). In the heat transfer model, thermal conductivities of chip materials are $0.151 \mathrm{~W} \mathrm{~m}^{-1} \mathrm{~K}^{-1}$ for PMMA, $5.605 \mathrm{~W} \mathrm{~m}^{-1} \mathrm{~K}^{-1}$ for TCP, $1.262 \mathrm{~W} \mathrm{~m}^{-1} \mathrm{~K}^{-1}$ for quartz glass (Table S3).

Accordingly, the temperature distribution in the central of the channel was introduced into the protein separation model. A simple 1-dimension model (see Figure S13) was used to calculate the protein content profiles. In this work, we only focused on the gel part which means the whole 1-dimension line was the gel and the background buffer was set as steady state. Here, we supposed the protein keep a constant charge value. The effective mobility of the protein could be calculated by the protein position at 
the different time from the experiment data according the eq 2. The surface charges of two model proteins at buffer $\mathrm{pH}$ were obtained by QIAGEN CLC Main Workbench (QIAGEN, Germany) and NCBI database. The potentials at anode and cathode were set as $100 \mathrm{~V}$ and $0 \mathrm{~V}$, respectively. The room temperature was $20{ }^{\circ} \mathrm{C}$. The effective mobility and diffusion coefficient of two model proteins as following were calculated based on the experimental result of the model protein separation (Figure 4). In TCP chip GE, $D_{\mathrm{Hb}}=2.152 \mathrm{e}^{-9} \mathrm{~m}^{2} \mathrm{~s}^{-1}, \mu_{\mathrm{Hb}}=1.520 \mathrm{e}^{-9} \mathrm{~m}^{2} \mathrm{~V}^{-1} \mathrm{~s}^{-1}, D_{\mathrm{Mb}}=2.528 \mathrm{e}^{-9} \mathrm{~m}^{2} \mathrm{~s}^{-1}, \mu_{\mathrm{Mb}}=1.985 \mathrm{e}^{-9} \mathrm{~m}^{2} \mathrm{~V}^{-1} \mathrm{~s}^{-1} ; \mathrm{In}$ PMMA chip GE, $D_{\mathrm{Hb}}=3.965 \mathrm{e}^{-9} \mathrm{~m}^{2} \mathrm{~s}^{-1}, \mu_{\mathrm{Hb}}=1.691 \mathrm{e}^{-9} \mathrm{~m}^{2} \mathrm{~V}^{-1} \mathrm{~s}^{-1}, D_{\mathrm{Mb}}=5.512 \mathrm{e}-9 \mathrm{~m}^{2} \mathrm{~s}^{-1}, \mu_{\mathrm{Mb}}=2.354 \mathrm{e}^{-9}$ $\mathrm{m}^{2} \mathrm{~V}^{-1} \mathrm{~s}^{-1}$. Initial band width was assumed to be $0.1 \mathrm{~mm} .{ }^{\mathrm{S} 1}$ And gel retardation factor of 0.35 is calculated according to the theoretical protein migration rate and the actual effective migration rate. The initial $\mathrm{Hb}$ and $\mathrm{Mb}$ contents were set as 0.0031 and $0.1176 \mathrm{mM}$ (for a better exhibition, the $\mathrm{Mb}$ content was reduced ten times in the figures). The initial band widths of protein were given $0.2 \mathrm{~mm}$ at the location of $1.4 \mathrm{~mm}$. The background buffer was set following the experimental conditions (Figure S13).

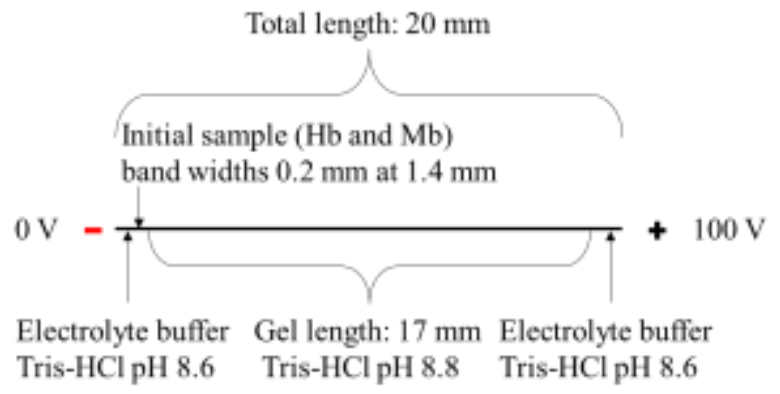

Figure S13. 1-dimension protein separation model.
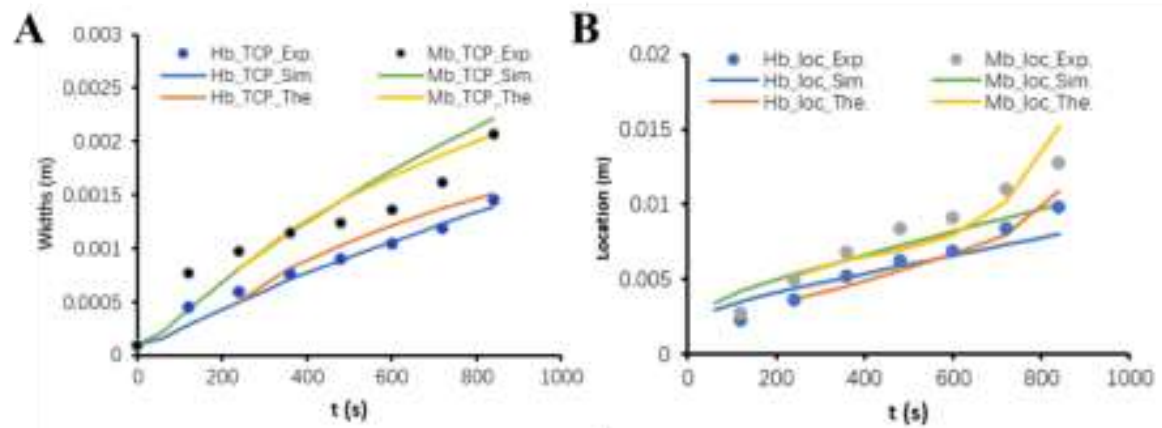

Figure S14. Comparations of (A) Band widths of $\mathrm{Hb}$ and $\mathrm{Mb}$ in experiment (with Exp. suffix), simulation (with Sim. suffix) and theoretical deduction (with The. suffix), and (B) Band locations of $\mathrm{Hb}$ and $\mathrm{Mb}$ in experiment (with Exp. suffix), simulation (with Sim. suffix) and theoretical deduction (with The. suffix).

In Figure S14, the band widths and migration positions of $\mathrm{Hb}$ and $\mathrm{Mb}$ shown obvious consistency in experiment, simulation and theoretical deduction, further validating above simulations and the theoretical model of eq 11.

The observation in Figure 4C revealed that there was an approximately linear relationship between the running time and the band width, nearly fitting the exponential function of $\boldsymbol{w}^{2}(t) \propto \boldsymbol{T t}$ as shown in Figure 
S14A. This might be caused by the following reasons. Firstly, the current observation time was too short and could not be used for a long-term observation of band width due to short chip lanes. It was calculated that if one wanted to detect a long-term band width from $100 \mathrm{sec}$ to $100,000 \mathrm{sec}$, the length of chip lanes should be increased from $20 \mathrm{~mm}$ to $200,000 \mathrm{~mm}$ for the observation. Currently, it was impossible for us to design such an electrophoretic chip with 200,000 mm lanes. Thus, within a short observation time, there was an approximate linearity between the running time and the band width. Secondly, the sensitivity of the CCD was poor, leading to the exact real band width was wider than the detected one due to protein diffusion. Thirdly, the real temperature was not constant due to balance of Joule heat generation and dissipation after certain time of GE run.

\section{S9. Blood samples and isoelectric focusing (IEF)}

The blood samples of suspected thalassemia were firstly assayed via blood routine examination and IEF, and were further confirmed by the molecular diagnosis of PCR in hospital. Then the blood samples from the patients of thalassemia were used as positive samples. The blood samples from healthy volunteers were firstly screened by blood routine examination and IEF as normal blood sample, and also confirmed by the molecular diagnosis of PCR. Then the healthy blood samples were used as the control sample, viz. the negative sample.
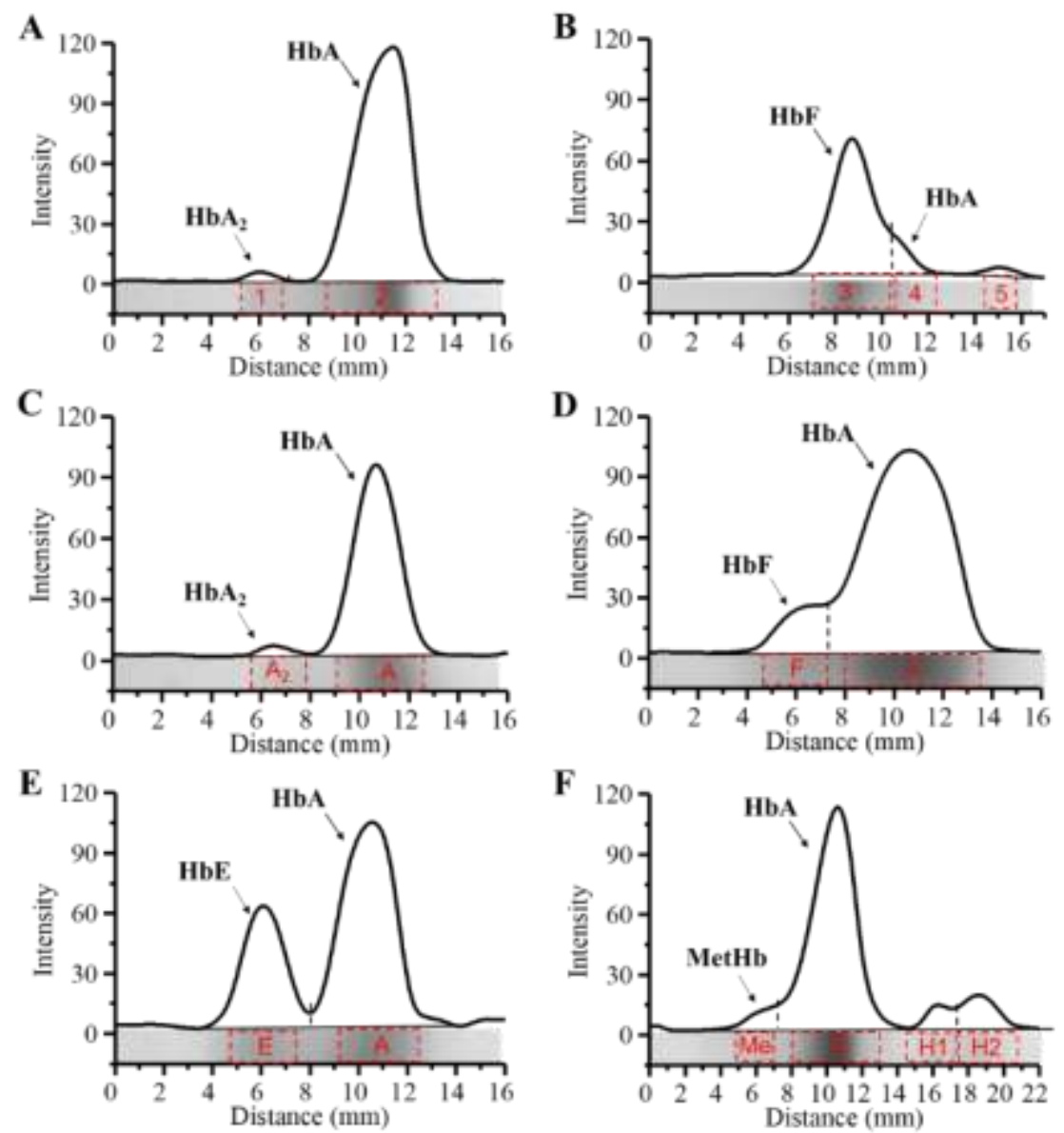

Figure S15. Alkaline gel electrophoresis of healthy adult blood (A), infant dried blood spot (DBS) (B), and $\mathrm{HbA}_{2}$ standard $(\mathbf{C})$, adult beta-thalassemia blood (D), adult $\mathrm{Hb}$ variant $\mathrm{E}$ blood (E), and adult 
alpha-thalassemia blood (F).

Table S4. Human blood hemoglobin assay and identification via TCP chip GE.

\begin{tabular}{|c|c|c|c|c|c|}
\hline Sample & Band & $\begin{array}{l}\text { TCP chip } \\
\text { results [\%] }\end{array}$ & $\begin{array}{l}\text { Reference } \\
\text { results a }{ }^{\mathrm{a}}[\%]\end{array}$ & $\begin{array}{l}\text { Dominant globin chain } \\
\text { (HRMS result) }\end{array}$ & $\mathrm{Hb}$ species/variants ${ }^{\mathrm{b}}$ \\
\hline \multirow[t]{2}{*}{ A } & 1 & 2.15 & 2.81 & $\delta, \alpha$ & $\mathrm{HbA}_{2}$ \\
\hline & 2 & 97.50 & 97.02 & $\alpha, \beta$ & $\mathrm{HbA}$ \\
\hline \multirow[t]{3}{*}{ B } & 3 & 90.60 & 92.50 & $\alpha, \gamma$ & $\mathrm{HbF}$ \\
\hline & 4 & 6.10 & 6.94 & $\alpha, \beta$ & $\mathrm{HbA}$ \\
\hline & 5 & 2.70 & - & $\alpha, \beta$ & Unknown \\
\hline \multirow[t]{2}{*}{$\mathrm{C}$} & $\mathrm{A}_{2}$ & 3.87 & 3.93 & - & $\mathrm{HbA}_{2}$ \\
\hline & A & 96.13 & 96.07 & - & $\mathrm{HbA}$ \\
\hline \multirow[t]{2}{*}{$\mathrm{D}$} & $\mathrm{F}$ & 9.38 & 8.79 & - & $\mathrm{HbF}$ \\
\hline & A & 90.10 & 90.22 & - & $\mathrm{HbA}$ \\
\hline \multirow[t]{2}{*}{$\mathrm{E}$} & E & 30.82 & 29.83 & - & $\mathrm{HbA}_{2} / \mathrm{E}$ \\
\hline & A & 64.97 & 67.99 & - & $\mathrm{HbA}$ \\
\hline \multirow[t]{4}{*}{$\mathrm{F}$} & Met & 4.00 & 7.93 & - & MetHb \\
\hline & A & 79.23 & 71.34 & - & $\mathrm{HbA}$ \\
\hline & H1 & 5.37 & 2.77 & - & $\mathrm{HbH}$ \\
\hline & $\mathrm{H} 2$ & 10.40 & 16.36 & - & $\mathrm{HbH}$ \\
\hline
\end{tabular}

${ }^{a}$ Reference results of sample A, B, C, D, E, and F were obtained by isoelectric focusing (IEF) method; ${ }^{b}$ $\mathrm{Hb}$ species discovered in sample A and B were analysed and identified by HRMS data (S5.2). Hb species in $\mathrm{C}, \mathrm{D}, \mathrm{E}$, and $\mathrm{F}$ were presumptively identified based on the relative position and percentage of common $\mathrm{Hb}$ variant patterns and data of sample $\mathrm{A}$ and $\mathrm{B} .{ }^{\mathrm{S} 3}$

An IEF Instrument (Shanghai BioChemAn Biotechnology, Shanghai, China) was used to perform human hemoglobin assay. Human blood sample was homolysed and diluted 1000 folds with deionized water and carrier buffer $(\mathrm{pH} 5.2-7.8) .25 \mu \mathrm{L}$ diluted sample was then loaded on a $30 \mathrm{~mm}$ IPG microcolumn ( $\mathrm{pH}$ 5.2-7.8) for $25 \mathrm{~min}$ rehydration. After that, the IPG microcolumn was inserted into the sample tray for IEF. Coolant liquid was injected into the tray to prevent overheating by Joule heat. Running program of IEF was set according to operation manual of instrument. Images were captured by online imaging system of the IEF Instrument and Mia analysis software (ver.2.0, BioChemAn Biotechnology Co. Shanghai, China).

\section{References}

S1 Vlassakis, J.; Herr, A. E. Joule Heating-Induced Dispersion in Open Microfluidic Electrophoretic Cytometry. Anal. Chem. 2017, 89, 12787-12796.

S2 Lide, D. R.; Kehiaian, H. V. CRC Handbook of Thermophysical and Thermochemical Data. CRC Press, 1994.

S3 Aliyeva, G.; Asadov, C.; Mammadova, T.; Gafarova, S.; Abdulalimov, E. Thalassemia in the laboratory: pearls, pitfalls, and promises. Clin. Chem. Lab. Med. 2019, 57, 165-174. 